\title{
Research on Agility Adjustment and Optimization of Application-oriented Undergraduate Specialty
}

\author{
Wenli Li \\ College of Business Administration, Jilin Engineering Normal University, Changchun 130012, \\ China
}

657010587@qq.com

\begin{abstract}
According to the changed of the application-oriented undergraduate education and development of economy and society demands, the higher education system is regarded as a manufacturing system of training talents by using agile manufacturing experience. According to this change of demand, there is a need to adopt the agility of the adjustment and optimization to the specialty construction. It necessary to construct the matrix organization of "school-branch", build a high quality teacher team with "multi-service", unify the teaching and research platform, and strengthen the information management in the universities.
\end{abstract}

Keywords: Application-oriented undergraduate; Specialty construction; Adjustment; Optimization; Agility

\section{应用型本科专业敏捷性调整与优化研究}

\author{
李文丽 \\ （吉林工程技术师范学院 工商管理学院，吉林省 长春市 130012）
}

摘要: 针对应用型本科专业与经济社会发展需求变化相脱节问题, 借鉴敏捷制造经验, 将高等教育系统视为一个生产人 才的制造系统, 将学科视为企业, 课程相当于虚拟组织中的核心资源, 根据需求变化, 对专业采取敏捷性调整与优化方式。 需要构建 “校一分院” 的矩阵式组织结构; 打造 “多面手” 的高素质教师团队; 统一教研与科研平台; 强化高校信息化管理。

关键词: 应用型本科; 专业建设; 调整; 优化; 敏捷性

中图分类号: G 648.4 文献标志码: A

引言

应用型本科教育是适应和满足区域经济发展需求的直接面向生产、建设、管理、服务等第一线的技术 实践需求的教育, 重点培养学生岗位适应能力及创新实践能力 [1]。要求学生所学专业与经济社会发展具 有高度融通性, 社会需求是影响应用型本科院校专业调整与优化的根本性原因 [2]。政府指令性的专业目 录调整造成突出问题是专业与产业的脱节、专业趋同、专业无特色等, 直接的后果是毕业生结构性失业 [3]。 目前, 多数高校的专业设置或调整时, 依据 “需求变化--专业调整--课程” 路径, 本质上仍然属于专业规 定课程的方式 $[4]$ 。带来的弊端是: 第一, 专业调整跟不上经济社会发展需求变化节奏; 第二, 跨学科、 跨院系的复合型人才培养困难很大。本文将制造业的敏捷性概念引入到高等教育人才培养体系中, 构建基 于敏捷性的专业调整与优化理论框架、方式及保障条件。

\section{1 理顺学科与专业关系}

学科是以知识的发现、整合、传递和应用为使命, 是一种知识的分类体系, 是大学的本体性的代表。 专业是不同课程的组合, 是对应于社会职业的分类, 它一定会对应到社会某一个行业、职业, 它是大学的 
工具性的代表 [5]。学科的发展以增进知识、不断地发现和创新新知识为目标, 专业建设以培养为社会服 务的人才为目标。学科是大学的组织, 专业不是组织, 是高校培养人才的一种方式。课程由学科中产生, 专业是课程的组成, 一个专业可由数十门课程组成, 这些课程来自于一个或不同学科, 课程是联系学科和 专业的桥梁。学科和专业相比, 学科更具稳定性, 实体性; 专业对接社会需求应该更加灵活性、虚拟性。 从知识层面看, 学科是集知识创造、知识存储为一体的知识库, 通过知识创造, 完成知识存量的增加与知 识更新的使命; 课程是知识的载体, 专业通过知识的输出与运用达到培养岗位要求人才的目标。

\section{2 构建敏捷化的专业调整与优化方式}

要想提高专业与经济社会发展需求的融合度, 第一, 在一定环境条件下, 保障知识创造--知识存储 -知识输出良性循环。没有学科支撑的专业必然会是陈旧的、肤浅的。第二, 就业需求快速变化情况下, 专 业必须具备一定灵活性。因此, 在经济社会发展需求变化约束下, 专业调整与优化必须具有敏捷性 [6]。

\section{1 敏捷性专业调整与优化理论框架}

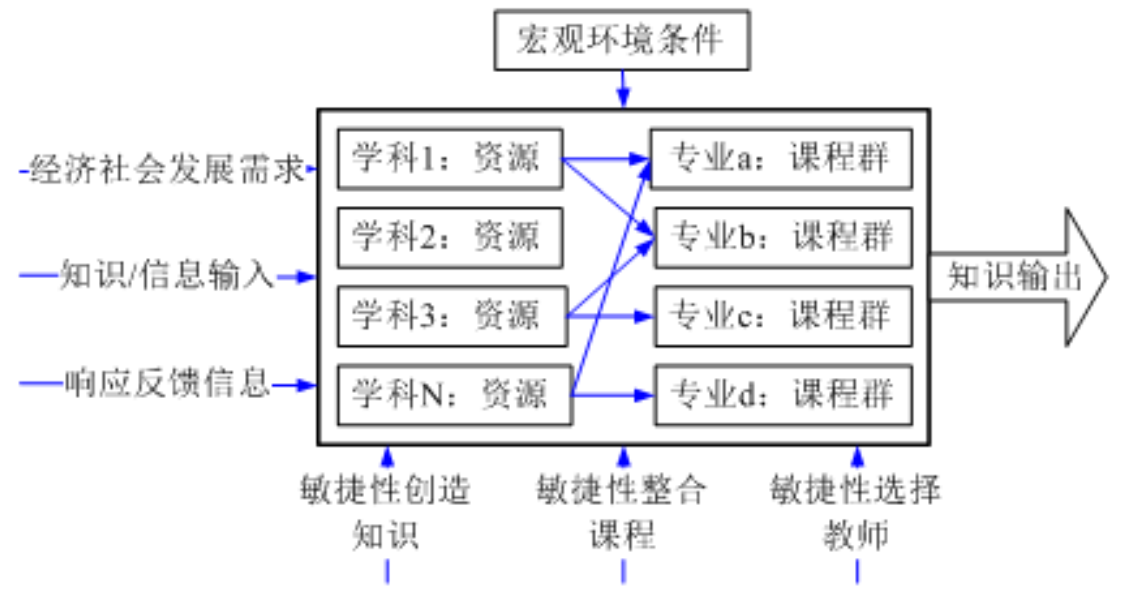

图 1 敏捷性的专业调整与优化研究框架

敏捷制造的实质是企业响应市场变化而快速组织资源的一种组织模式。以信息为基础, 通过契约连接, 将各个企业核心资源整合到一个虚拟企业中, 运用动态联盟方式, 快速生产出满足消费者需要的产品, 敏 捷性能使企业以更快的速度、更好的质量、更低的成本和更优质的服务来赢得市场竞争。高校教育系统与 生产制造系统非常类似, 高校教育体系中, 输入知识, 输出的是人才, 社会对人才的需求愈发呈现多样性、 变化性特征, 因此敏捷性专业调整与优化是适应人才需求的有效途径。

如图 1 所示，借用敏捷制造理念，将高等教育系统视为一个生产人才的制造系统，学科相当于参与提 供核心资源的企业，专业类似于由课程构建的虚拟组织。高校由众多学科构成，也就相当于具有差异优势 的企业集团。专业调整要根据经济社会需求变化, 到学科中整合课程或者课程群。这种构建专业方式是一 种动态联盟，具有动态性、优势互补性及开放性特征。

\section{2 需求导向下敏捷性的专业调整与优化方式选择}

根据经济社会发展需求变化情况，对专业进行调整与优化。如表 1 所示，当市场对某类人才需求规模 不够大, 但需求量及岗位对知识、技能要求比较稳定时, 运用学科资源创造知识满足市场需求, 从时间和 成本具有可行性, 可以采取上文所述的组合课程或敏捷性创造知识的方式进行专业调整或优化; 当市场需 
求量不大, 而且预测未来需求量波动较大时, 创造知识需要一定周期, 难以跟上需求变化速度, 这时可以 通过技能培养包方式对专业进行优化。所谓技能培养包就是在现有知识、课程存量来不及变化情况下，柔 性组合课程响应需求变化的课程包。比如旅游管理岗位需要懂计算机应用、会茶艺、插花的酒店管理知识 和技能的学生，这时可以将计算机应用、茶文化、茶艺表演、插花技能等课程打包到一起，有针对性地进 行授课, 补充原有课程设置的不足。对于非跨学科调整的专业, 除了可以采用柔性技能培养包外, 也可以 对授课内容进行调整, 强化学生某项技能。另外, 应对短期波动, 需要学科建设上加强预测, 把握变化动 态; 将最新研究成果融入到原有课程中。

当市场对某类人才需求量很大且稳定，进行敏捷性专业调整与优化时间、资源等条件相对容易获取， 因此无论是跨学科还是学科内都可以采用敏捷方式进行知识创造及形成新课程。当市场对某类人才需求量 很大, 但是这类岗位会随着市场波动, 具有不稳定性, 属于短期需求量大的岗位, 这时候需要做好学科发 展方向及职业发展需求预测，打好提前量做好知识创新及储备工作。短期应对方式应采取技能培养包及课 程组合方式。

表 1 需求变化与专业调整方式

\begin{tabular}{|l|l|}
\hline 岗位需求 & \multicolumn{1}{c|}{ 调整方式 } \\
\hline 有一定需求量, 科急定 & 组合课程; 敏捷性创造知识。专调整、优化 \\
\hline 有一定需求量, 变化 & $\begin{array}{l}\text { 柔性技能培养包; } \\
\text { 加强预测, 把握变化动态; 将最新研究成果融入到原有课程中。 }\end{array}$ \\
\hline 需求量大, 稳定 & 敏捷性创造知识, 形成新课程。 \\
\hline 需求量大, 变化 & $\begin{array}{l}\text { 长期: 加强预测; 做好知识创造及储备 } \\
\text { 短期: 柔性技能培养包、课程组合。 }\end{array}$ \\
\hline
\end{tabular}

\section{3 专业调整与优化的保障条件}

\section{1 构建 “校一一分院” 的矩阵式组织结构}

为了保证知识创造、课程建设、专业调整与优化与社会、经济发展相适应, 高校内部组织结构要进行 调整。减少管理层，缩短信息上下、内外传递路径，消除横向信息传递隔阂，加大横向部门的合作。成立 专门的专业管理委员会, 构建 “校--分院” 的二级矩阵制组织结构。专业管理委员会是常设校级组织, 除 了固定委员外, 其他人员是根据学科、专业发展需要，从校学科办、招生就业处、师资处、财务处、教务 处、科研处等各个职能部门及分院临时组成, 保障组织运行灵活性。管理重心在于知识创造及学科建设, 专业构建相对学科, 要去实体化, 运行更灵活。

\section{2 打造 “多面手” 高素质教师团队}

实施敏捷调整专业过程中应该最大限度地调动、发挥教师的主观能动性。使其从一般教书匠向敏捷型 教师的转变, 使教师变成创造知识、传授知识、使用知识为一体的 “多面手”。加强教师培训体系的改造 和完善, 终生学习理念必须贯彻到基层学术组织中; 构建知识的 “创造-传授-使用” 全过程教师评价体系, 
引导教师向 “多面手” 方向发展; 发挥高职称、高学历教师传帮带作用, 打造优秀教师团队; 做好优秀人 才引进工作，及时补充学科建设、专业建设师资力量。

\section{3 统一教研与科研平台}

在应用型本科高校, 培养社会经济发展需要人才目标指引下, 教研与科研不应该是割裂的 [7]。要完 成敏捷化调整与优化专业的任务, 教研与科研的目标必须一致, 保证知识创造与专业构建协调发展跟上岗 位需要, 应用型本科高校打造打造教科研统一平台, 在学科建设导向下, 将所有学术资源引导到一个平台 上，使学科成果真正为专业建设服务、为本科教学服务 $[8]$ 。

\section{4 强化高校信息化管理}

加强信息技术在高校的使用，最重要的是建立起信息管理体系，高度重视校企合作，拓展信息获取渠 道, 研究制订高校信息化的整体规划和技术方案 [9]。建立畅通的高校信息网不同学科间实现信息交换和 共享, 同时逐步将不同分院和学科有关资源情况、实验设备能力等信息上网, 在 “竞合/协同” 的前提下 跨学科、跨学校选择合作伙伴, 利用信息技术持续不断地为用人单位提供具备不同知识和技能的学生信息 $[10]$ 。

\section{4 致谢}

本研究工作受到吉林省教育科学规划办公室（课题名称：高校转型背景下职业师范类院校的敏捷性专 业设置于调整模式研究）和吉林工程技术师范学院的资助，特此感谢。

\section{Acknowledgements}

This work was financially supported by Education Science Planning Office in Jilin Province (Subject Title: A study on the setting and adjustment model of the agility specialty in Vocational Colleges under the background of transformation and development of colleges and universities in China) and Jilin Engineering Normal University.

\section{参考文献:}

[1] 潘惁元, 车如山. 略论应用型本科院校的定位 $[J]$. 高等教育研究, 2009 (5) :36-37.

[2] 尤伟, 颜晓红, 陈鹤鸣. 我国应用型本科院校专业设置与调整机制变迁 [J]. 江苏高教, 2015 (5) : 68.

[3] 吴琴. 应用型本科院校专业设置及调整机制研究 [J]. 中国成人教育, 2016 (10) :82-83.

[4] 常思亮. 大学专业与课程关系的两种模式解析 [D]. 湖南: 湖南师范大学. 2009:2

[5] 叶飞帆. 敏捷高等教育初探--基于学科与专业的视角 [J].高等教育研究, 2011 (12) :29.

[6] 魏小琳. 基于敏捷性的本科专业设置机制建设与研究 [J]. 中国大学教学, 2013(12) :52-53.

[7] 魏小琳. 基于敏捷性的本科专业设置机制建设与研究 [J]. 中国大学教学, 2013 (12):52-53.

[8] 吴琴. 应用型本科院校专业设置及调整机制研究 [J]. 中国成人教育, 2016 (10):83

[9] 沈健. 江苏应用型本科院校人才培养的若干思考 [J]. 江苏高教, 2014(4):6-9.

[10]沈健. 江苏应用型本科院校人才培养的若干思考 [J]. 江苏高教, 2014(4) :6-9.

\section{References:}

[1] Pan Maoyuan, Che Rushan. Positioning On the applied universities [J]. Higher Education Research, 2009 (5): 36-37.

[2] You Wei, Yan Xiao-hong, Chen Heming. Professional setting and adjustment mechanism of 
applied undergraduate colleges in China [J]. Jiangsu Higher Education, 2015 (5): 68.

[3] Wu Qin. Research on major setting and adjustment mechanism in application professional colleges [J]. China Adult Education, 2016 (10): 82-83.

[4] Chang Siliang. University of professional and curriculum relationship between the two models [D]. Hunan: Hunan Normal University. 2009: 2

[5] Ye Feifan. Study on agile higher education - based on the perspective of discipline and specialty [J]. Higher Education Research, 2011 (12): 29.

[6] Wei Xiaolin. Based on the agility of the undergraduate professional setting mechanism construction and research [J]. China University teaching, 2013 (12): 52-53.

[7] Wei Xiaolin. Based on the agility of undergraduate professional setting mechanism construction and research [J]. China University teaching, 2013 (12): 52-53.

[8] Wu Qin. Research on the specialty setup and adjustment mechanism of applied undergraduate universities [J] .Chinese Journal of Adult Education, 2016 (10): 83

[9] Shen Jian. Some thinking on Jiangsu applied undergraduate institutions of personnel training [J]. Jiangsu Higher Education, 2014 (4): 6-9.

[10] Shen Jian. Some thinking on Jiangsu applied undergraduate institutions of personnel training [J]. Jiangsu Higher Education, 2014 (4): 6-9. 